\title{
Cancer research and therapy: Where are we today?
}

\author{
Sampada Sawant ${ }^{1}$, Ranjita Shegokar ${ }^{2}$

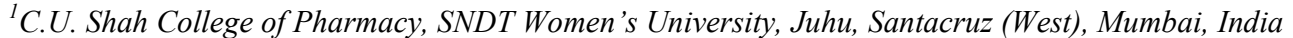 \\ ${ }^{2}$ Department of Pharmaceutics, Biopharmaceutics and NutriCosmetics, Freie Universität Berlin, Berlin, Germany
}

Received June 26, 2014; Revised October 15, 2014; Accepted October 16, 2014; Published Online October 19, 2014

\section{Review Article}

\begin{abstract}
Till date scientists are struggling to understand the complete mechanism of carcinogenesis. In future, the real time detection of cancer may help scientists to identify some of the complicated biological mechanisms. Certain special features of cancer cells enable researchers to deliver the drug or to develop the right drug therapy. These cell properties include over expression or over activity in uptake of certain nutrients e.g. folic acid and increased permeability. Listed properties might vary depending upon the type of cancer and can be fully exploited by using nanoparticles either to detect the site of cancer or to direct the drug at the affected site. Product approach like drug conjugates, complexes serves as a good platform to solve issues like solubility, toxicity, poor penetration and stability related to cancer drugs. Beside this, several drug delivery platforms are under development by researchers in academia as well as in industry to deliver therapeutic molecules and new chemical entities to the targeted site in body. Amongst them, nanotechnology both at molecular and supramolecular level is a leading platform and can help to image, detect and treat cancer. Surface modification of nanoparticles by coating or anchoring their surface with special markers, materials, peptide, proteins, antibodies or antigens add extra feature and thereby can enhance the effectiveness. These treatments can be used individually or in combined form. In this review, advances on nanotechnological platform are discussed together with some assisting techniques like magnetic field, photo or light field, sonic rays are touched upon. New biological therapies that are advancing in this direction include the antisense therapy, cell therapy, gene therapy, radiation therapy and SiRNA interfaces which are discussed in brief in this article. This article gives short overview on use of complementary and alternative medicine for treatment of cancer such as traditional Chinese medicine (TCM), Ayurveda to avoid toxic effects of synthetic drugs.
\end{abstract}

Keywords: Cancer Therapy; Nanoparticles; Targeting Drugs; Surface Modification; Gene Therapy; Vaccines; Herbal Actives; Personalized Medicine

\section{Introduction}

Cancer remains a leading cause of death worldwide with an estimated 14.1 million new cancer cases and 8.2 million cancer-related deaths in 2012, compared with 12.7 million infections, in 2008. Cancer cases worldwide are predicted to increase by $70 \%$ over the next two decades, according to the World Health Organisation. ${ }^{1}$ Cancer mortality is the top killer with breast and cervical cancer as the lead cause. Since the 2008 estimates, breast cancer incidence has increased by more than $20 \%$, while mortality has increased by $14 \%$ and is the most frequently diagnosed cancer among women in 140 of 184 countries worldwide. Cervical cancer is the fourth most common cancer affecting women worldwide, after breast, colorectal, and lung cancers; it is most notable in the lower-resource countries of sub-Saharan Africa.

Years of intense biomedical research and billions of dollars spent in cancer research have increased the understanding of the underlying mechanisms of tumorigenesis and cancer biology. Although, despite advances in surgical and radiation treatments, chemotherapy continues to be an important therapeutic option for different malignancies, especially for the primary, advanced and metastatic tumors. However, the efficacy of chemotherapy is substantially limited by the intrinsic and acquired resistance of cancer cells to anticancer drugs. Resistance to chemotherapy is due to the variety of factors such as individual variations in patients (e.g. age, gender) and genetic differences in tumors. The most common reason of resistance to drugs is the change in the expression of one or more energy-dependent transporters, insensitivity to drug-induced apoptosis and induction of drug-detoxifying effects.

Chemotherapy is used for the whole-body treatment of recurrent tumors using conventional anticancer drugs which lead to serious clinical side effects. ${ }^{2}$ The side effects are mainly associated with the high dose, non-specific distribu- 
tion, severe toxicity to the normal cells, inadequate drug concentrations at tumors or cancerous cells, and the development of multidrug resistance. Therefore, continuous research for improved anti-cancer therapies that can selectively target tumor cells with minimal side effects on normal tissues is going on. ${ }^{3}$

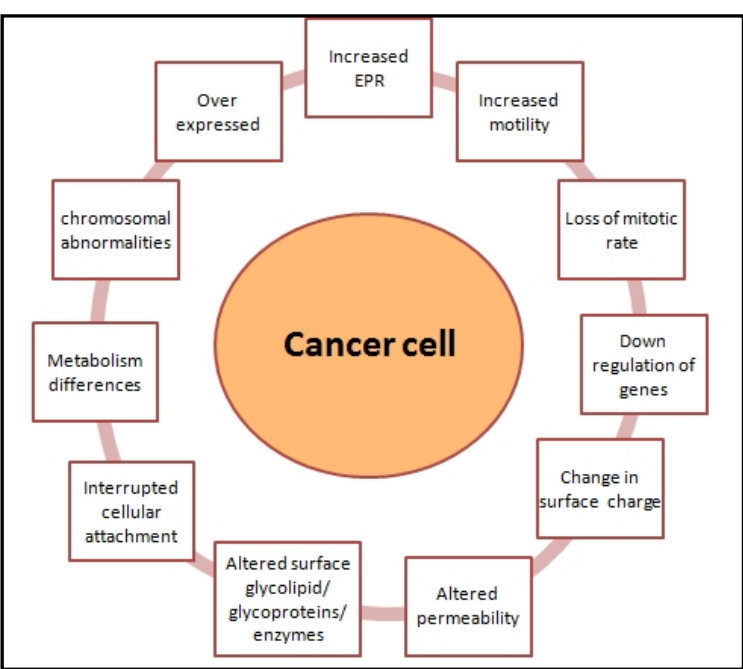

FIG. 1: The anatomical and physiological factors which play important role in drug therapy and can be used for drug targeting

Several approaches like immunotherapy, thermal therapy, phototherapy and gene therapy have been recently developed and tested for the suppression of such resistance. However, their efficacy fluctuates significantly in patients due to the differences of drug resistance mechanisms in patients. The individualized selection of drug doses and targets to suppress resistance based on the molecular characteristics of tumors might potentially improve the treatment outcome and bring us closer to an era of personalized medicine. Non-invasive detection and treatment of most common types of cancers are now in the hold of the scientists.

Recent years have seen accelerated application of nanotechnology to the prevention, biodiagnosis, drug delivery and treatment of cancer. Several types of nanocarriers that have been synthesized for drug delivery include dendrimers, liposomes, solid lipid nanoparticles, polymersomes, polymer-drug conjugates, polymeric nanoparticles, nanocrystals, peptide nanoparticles, micelles, nanoemulsions, nanospheres, nanoshells, carbon nanotubes, and gold nanoparticles, etc. In these types of delivery systems, drugs can be entrapped inside, dissolved in the matrix, covalently linked to the backbone, or absorbed on the surface.

This review discusses the recent developments in drug delivery sciences used in cancer therapy. Novel delivery systems have made possible the clinical use of new therapeutics, significantly reduced side effects and have enabled new and better chemotherapeutic regimens using existing pharmaceuticals. Drug delivery systems have also facilitated cancer prevention as well as the pain management associated with cancer progression and chemotherapy. Discussions are also extended to other therapeutic approaches like vaccines, plasma treatment and stem cells.

TABLE 1: Overview of anticancer drugs, their solubility and respective nanoparticles studied in literature.

\begin{tabular}{|c|c|c|}
\hline Drug & Solubility & Novel carriers developed \\
\hline Doxorubicin & $10 \mathrm{mg} / \mathrm{ml}$ & $\begin{array}{l}\text { SLNs, Liposomes, Chain NP, } \\
\text { Polyamino acid NP, Carbon } \\
\text { nanotubes }\end{array}$ \\
\hline Edelfosine & $15 \mathrm{mg} / \mathrm{ml}$ & SLNs \\
\hline Paclitaxel & $0.3 \mathrm{mg} / \mathrm{ml}$ & PLGA nanoparticles \\
\hline Retinoic acid & $<1 \mathrm{mg} / \mathrm{ml}$ & NLCs \\
\hline Gemcitabine & $25 \mathrm{mg} / \mathrm{ml}$ & Liposomes, Gold nanoparticles \\
\hline $\begin{array}{l}\text { Vincristine } \\
\text { sulphate }\end{array}$ & $25 \mathrm{mg} / \mathrm{ml}$ & Liposomes \\
\hline Oxiplatin & $7.9 \mathrm{mg} / \mathrm{ml}$ & Liposomes, SLNs \\
\hline Docetaxel & $0.25 \mu \mathrm{g} / \mathrm{ml}$ & Hydrogel \\
\hline Bufalin & - & Chitosan nanoparticles \\
\hline Irinotecan $\mathrm{HCl}$ & $25 \mathrm{mg} / \mathrm{ml}$ & SLNs \\
\hline Cisplatin & $0.25 \mu \mathrm{g} / \mathrm{ml}$ & Hydrogels \\
\hline Temsirolimus & $20 \mu \mathrm{g} / \mathrm{ml}$ & Hydrogels \\
\hline Carmustine & $4 \mathrm{mg} / \mathrm{ml}$ & Chemotherapy Wafers \\
\hline Etoposide & $0.2 \mathrm{mg} / \mathrm{ml}$ & SLNs, PLGA nanoparticles \\
\hline
\end{tabular}

\section{Drug delivery systems are classified depending on their} way of manufacturing or starting material

As nanoparticles (50 $\mathrm{nm}$ or less) can easily enter the cells and the organelles and interact with DNA, proteins, enzymes and cell receptors extracellularly and intracellularly. Smaller nanoparticles $(\leq 20 \mathrm{~nm})$ can move out of blood vessels and circulate throughout the body. Since all the biological processes that lead to cancer occur at the nanoscale and inside the cells, nanotechnology offers tremendous potential for the detection and treatment of disease (Figure 1). The main scope of this article is to understand the impact of nanoparticles in cancer therapy and discuss the recent advances and pitfalls. In the following sections, nanocarriers that have been widely explored for cancer therapy are discussed one by one followed by discussion on most advanced therapies under research. Table 1 lists some typical anticancer drugs and respective drug delivery systems developed.

\section{Lipid based Nanocarriers}

\section{Solid Lipid Nanoparticles (SLNs)}

SLNs (50 - $1000 \mathrm{~nm}$ ) introduced in the early nineties represents an alternative carrier system to traditional colloidal carriers, such as emulsions, liposomes and polymeric microand nanoparticles. SLN are mainly stabilized by combination of surfactants or polymers and their mixtures. The two basic production methods are (1) the hot homogenization technique and (2) the cold homogenization technique.

Aznar et al. have reported edelfosine lipid nanoparticles, ET - NP, (150 nm, zeta potential - $27.07 \mathrm{mV})$ for the treatment 
of breast cancer cells. ${ }^{4}$ Edelfosine was encapsulated in Precirol $\mathrm{ATO}^{\circledR} 5$ lipid nanoparticles, by the hot homogenization method followed by high shear homogenization and ultrasonication. The optimized ET-NP was effective in inhibiting the proliferation of MCF7 breast cancer cell line at an IC50 concentration of $12.9( \pm 2.23) \mu \mathrm{g} / \mathrm{mL}$. The developed drug nanoparticles were 1.37 times more effective in inducing cell death in MCF7 cells than the free drug, and produced a remarkable decrease in cell viability. The data presented in this paper provided evidence that entrapping ET in NP entailed an improvement in its efficacy when treating MCF7 breast cancer cells, leading to a moderate cell cycle arrest. Besides, ET-NP induced apoptosis in a time- and dose-dependent manner to a greater extent in comparison with the treatment using the free drug, suggesting that encapsulating ET in LN was essential to improve the efficacy of the drug.

In another separate study doxorubicin (Dox)-loaded SLNs were prepared. 5 The acidic environment of the endocytic cells accelerated the release rate of the drug from SLNs. In addition, no haemolytic activity was observed from the SLNs up to $1.0 \mathrm{mg} / \mathrm{mL}$, implying that SLNs are themselves safe for inclusion in intravenous injections. Dox responsiveness to MCF-7/ADR cells (ovarian cell line) is lower than that in MCF-7 cells, because P-glycoprotein is highly expressed in MCF-7/ADR cells. SLNs accumulated in MCF- 7/ADR cells to a greater extent than did Dox alone. The relative cellular uptake was 17.1-fold (60 minutes) and 21.6-fold (120 minutes) higher than that of Dox, implying that P-glycoprotein-mediated drug efflux was diminished by the introduction of SLNs. SLNs or Dox treatment alone did not induce cell death in MCF-7/ADR cells over the drug concentrations up to $10 \mu \mathrm{M}$, whereas 10 and $30 \mu \mathrm{M}$ SLN-Dox decreased MCF-7 cell viability. These results indicated that SLNs efficiently caused cell death through the induction of apoptosis in Dox resistant cancer cells, by inducing a greater accumulation of Dox in the cells.

\section{Nanostructured Lipid Carriers (NLCs)}

NLCs show a higher loading capability by conceiving a less organized solid lipid matrix, i.e. by blending a fluid lipid with the solid lipid, a higher element drug stacking can be achieved. Thus, the NLCs have high drug loading capacity and drug expulsion during storage is less. The EPR effect takes advantage of NLCs for passive targeting. With the improvement in surface-engineering expertise, the biodistribution of NLCs can be further manipulated by modifying the physicochemical properties of NLCs.

ATRA was incorporated in the NLCs for treatment of chemo-resistant ovarian cancer. ${ }^{6}$ ATRA controls cancer progression with its unique cell-differentiating, anti-proliferative and apoptosis inducing activities mediated by the retinoic acid receptors and retinoid $\mathrm{X}$ receptors. ${ }^{7}$ This drug is therefore officially approved for the treatment of acute promyelocytic leukemia, a subtype of blood cancer. The delivery of ATRA is mainly limited by its poor physico-chemical properties (e.g. high lipophilicity: $\log \mathrm{P}=6.3$ and low aqueous solubility: $29 \mu \mathrm{g} / \mathrm{ml}$ ) and unfavourable pharmacokinetic behaviours (e.g. non-specific binding: serum binding > 95\%, VD > 100 L; short half-life: $\mathrm{t}_{1 / 2}=0.5-2 \mathrm{~h}$ ). Polymer-oil nanostructured carriers (PONC) that are designed for systemic delivery of ATRA have been reported. PONC were prepared using standard emulsification-solvent evaporation technique. The PONC's (170 - $280 \mathrm{~nm}$ and PDI $0.10 \pm 0.02$ ) were studied in ovarian cancer cell subline SKOV-3PR that could withstand up to $300 \mathrm{nM}$ paclitaxel and expressed high levels of multidrug resistance transporter ABCB1 and tumorigenic marker CD133. Differential scanning calorimetry of PONC revealed superior polymer amorphous nature and dispersion of the entrapped ATRA. The ATRA encapsulation efficiency was increased up to 8.5-fold and a 5-day controlled release profile was obtained. ATRA-PONC was able to induce extensive apoptotic cell death and exert substantially higher long-term anti-tumorigenic effects (IC50 of ATRA-PONC: $2 \mu \mathrm{g} / \mathrm{ml}$ versus free ATRA: $17.5 \mu \mathrm{g} / \mathrm{ml} ; \mathrm{p}<$ 0.05) in SKOV-3PR cells. Mechanistic studies indicated that these enhanced anticancer effects were due to higher cell permeation by the well-dispersed drug/oil steadily released from PONC.

\section{Liposomes}

Liposomes are versatile, self-assembling, carrier materials that contain one or more lipid bilayers with phospholipids and/or cholesterol as major lipid components, and can be used to encapsulate hydrophilic drugs in their inner aqueous compartment(s) while more hydrophobic drugs can associate with the lipid bilayer(s). Liposomes have been shown useful for drugs with unfavourable pharmacokinetic properties that result in a suboptimal therapeutic index. Liposome size is usually limited to $50-150 \mathrm{~nm}$ when used for drug delivery purposes. Doxorubicin (Dox) is associated with several side effects, most notably cardiotoxicity, and liposomal delivery of doxorubicin has proved to be useful to reduce chronic cardiotoxicity. Liposomal delivery also increases the therapeutic index of the drug. Indeed, liposomal doxorubicin has been clinically approved for the treatment of Kaposi's sarcoma, ovarian cancer, breast cancer and multiple myeloma (as PEG-liposomal doxorubicin marketed as Doxil ${ }^{\circledR}$ in the USA and Caelyx outside the USA) and for advanced breast cancer (the non-PEGylated liposomal doxorubicin version marketed as Myocet). ${ }^{8}$ Liposomal delivery of gemcitabine allows a massive dose reduction while yielding similar antitumor effects as a 45-fold higher free gemcitabine dosage. Liposomal gemcitabine almost completely arrests prostate cancer xenograft growth whereas liposomal doxorubicin only seems to slow it down. ${ }^{9,10}$

Vincristine sulfate is used in treatment of childhood and adolescent leukemia ${ }^{11}$ and lymphoma. Vincristine-induced 
dermal toxicity is significantly reduced when the drug is delivered via liposomes. ${ }^{12}$ Aroplatin ${ }^{\circledR}$ (Antigenics Inc., Lexington, MA, USA) is a multilamellar liposomal formulation of saturated phospholipids dimyristoyl phosphatidylcholine (DMPC) and dimyristoyl phosphatidylglycerol (DMPG) bearing oxaliplatin ${ }^{13}$ and shows reduced nephrotoxicity. ${ }^{14}$ In order to achieve prolonged and sustained drug delivery, conventional liposomes are surface modified with inert, biocompatible, hydrophilic polymers such as PEG. Pegylated liposome containing doxorubicin named Doxil ${ }^{\circledR} / \mathrm{Caelyx}^{\circledR}$ is the first stealth liposomal formulation to be approved in USA and Europe for treatment of Kaposi's sarcoma and recurrent ovarian cancer. Figure 2 shows typical fate mechanism of bare and stealth nanoparticles. Sterically stabilized liposomes containing doxorubicin (Doxil ${ }^{\circledR}$ Johnson \& Johnson) modified with monoclonal nucleosome (NS)- specific 2C5 antibody (mAb 2C5) have shown improved antitumor efficacy. ${ }^{15}$ Liposomes bearing both folic acid and a monoclonal antibody against endothelial growth factor receptors (EGFR) have been reported for effective and specific in vitro delivery of doxorubicin. ${ }^{16}$ Thermo-sensitive vesicles utilizes phospholipids having phase transition temperature between 41 $42^{\circ} \mathrm{C}^{17}$ and undergo gel-to-liquid crystalline transitions ${ }^{18}$ or with leucine zipper sequence peptide which dissociates above its melting temperature $\left(\sim 40^{\circ} \mathrm{C}\right)$ into a disordered conformation. ${ }^{19}$

\section{Nanocapsules}

Nanocapsules are vesicular systems that consist of an oily core covered by a polymeric or lipidic shell. These structures have been exploited for the encapsulation of highly hydrophobic anticancer drugs, such as etoposide, paclitaxel, or docetaxel. Lollo et al. ${ }^{20}$ have constructed PGA-PEG nanocapsules for the delivery of docetaxel consisting of an oily core and a polymer shell made of a polyglutamic acid-polyethylene glycol (PEG-PGA) grafted copolymer with 24\% w/w PEG content. PGA-PEG nanocapsules were prepared by using modified solvent displacement technique that involved the deposition of the coating polymer onto the oily core mainly by electrostatic interaction.

The nanocapsules $(200 \mathrm{~nm})$ were negatively charged with $90 \%$ encapsulation efficiency. In vivo antitumor activity of docetaxel-loaded PGA-PEG nanocapsules resulted in significant decrease in the tumor growth $(\mathrm{p}<0.01)$ compared to that of Taxotere (docetaxel, Sanofi-aventis U.S. LLC) in mice. Nanocapsules are studied to a limited extent for cancer treatments.

\section{Polymer based Nanoparticles}

\section{Polymeric Nanoparticles}

Polylactic glycolic acid (PLGA) nanoparticles being biocompatible offers efficient drug targeting at the cellular level and is the most widely studied polymeric particle. ${ }^{21}$ However, cellular uptake of PLGA nanoparticles is of low capacity and specificity. ${ }^{22,23}$ These drawbacks of PLGA nanoparticles can be overcome by its conjugation with specific ligands like Wheat Germ Agglutinin (WGA) that specifically recognize and bind rapidly with $\mathrm{N}$-acetyl glucosamine and sialic acid residues on cell membrane. ${ }^{24} \mathrm{WGA}$ therefore has the potential to be a good ligand for the targeted delivery of anticancer drugs to the colon.

Wang and co-workers, developed PLGA nanoparticles (PNP) decorated with WGA lectin to enhance paclitaxel delivery to colon cancer cells by a modified emulsion solvent evaporation method. ${ }^{25}$ The WGA decorated nanoparticles (WNP) had a particle size of $330 \mathrm{~nm}$ and polydispersity index of 0.16 . The paclitaxel formulations were evaluated for cytotoxic activity in the range of $0.05-50 \mu \mathrm{g} / \mathrm{ml}$. The drug-free PLGA nanoparticles did not show any detectable cytotoxicity as they did not reduce cell viability to below $80 \%$. The MTT assay suggested that the WNP and PNP formulations yielded comparable paclitaxel IC50 values against the Caco-2 cells at the end of $24 \mathrm{~h}$. Enhanced cell-killing effects were observed for WNP upon prolongation of the incubation time to $72 \mathrm{~h}$, leading to IC50 value reduction to $0.087 \mu \mathrm{g} / \mathrm{ml}$. The Caco-2 and HT-29 cells exhibited an uptake and post uptake retention preference that ranked in the order of WNP > PNP. These results suggested that the formulation of paclitaxel into WGA-conjugated nanoparticles enhanced paclitaxel uptake and resulted in higher drug retention by the cancerous colon cells.

\section{Chitosan nanoparticles}

Chitosan is a linear polysaccharide with several commercial and possible biomedical uses. Owing to its biocompatibility and biodegradability, chitosan has been widely used as polymer materials for the modification and delivery of several anticancer drugs, i.e., chitosan nanoparticles (CS-NPs). ${ }^{26}$ Their small size enables them to pass through biological barriers in vivo (such as the blood-brain barrier) and delivering drugs to the lesion site to enhance efficacy. Chitosan nanoparticles can be readily modified and have attracted increasing attention of scientists, for example, loading protein drugs, gene drugs and anticancer drugs.

Biotinylated chitosan nanoparticles loaded with Bufalin (Bu-BCS-NPs) were tested for targeted therapy against breast carcinoma. ${ }^{27}$ Biotin is a water-soluble vitamin with roles in cell growth, signal transduction and many other cellular functions. Several tumor cells express sodium dependent multivitamin transporter (SMVT) to receive biotin for rapid tumor growth, and biotinylation of chitosan nanoparticles can be used to enhance the binding/affinity of macromolecular drugs to tumor cells, leading to increasingly effective antitumor therapy. 
Bufalin is known to induce cell cycle arrest and apoptosis in cancer cells. The Bu-BCS-NPs were prepared by solvent-dialysis method wherein NPs were formed with the core of hydrophobic bufalin and surrounded by CS as the outer surface facing water. Bu-BCS-NPs (50-200 nm) were studied for anti-tumor activity in human breast cancer MCF-7 cells and exhibited an IC50 of $58.2 \mathrm{ng} / \mathrm{ml}$ compared to that of free bufalin $(189.6 \mathrm{ng} / \mathrm{ml})$ and 3 times increased antitumor effect. The formulation of bufalin as BCS-NPs allowed water solubility, slow and sustained release of bufalin, tumor targeting and rapid intracellular uptake.

\section{Metal nanoparticles}

In cancer, it would be ideal to administer multiple drugs with use of simultaneous non-invasive methods. In cancer therapy, targeted delivery in a localized way is one of the key challenges. It is anticipated that nanoparticle-mediated targeted delivery of drugs might significantly reduce the dosage of the anticancer drugs with better specificity, enhanced efficacy and low toxicities. Gold and its compounds are reported widely for their biomedical applications in literature. ${ }^{28,29}$ The earliest medical use of gold can be traced back to the Chinese in $2500 \mathrm{BC}$. They were the first to prepare and use red colloidal gold as the, "drug of longevity." Red colloidal gold is still in use today in many Asian countries for rejuvenation and revitalization. Nanomaterials, especially gold nanoparticles (AuNPs) have unique physico-chemical properties, such as ultra-small size, large surface area to mass ratio, and high surface reactivity, presence of surface plasmon resonance bands, biocompatibility and ease of surface functionalization. Gold nanoparticles (AuNPs) have exceptional stability against oxidation and therefore will play a significant role in the advancement of clinically useful diagnostic and therapeutic nanomedicines.

Gold nanoparticles ( $\sim \mathrm{nm})$ for targeted delivery of gemcitabine and cetuximab (C225) anti-epidermal growth factor receptor (EGFR) antibody as the targeting agent in the treatment of pancreatic cancer, using $\mathrm{NaCl}$ incubation method is reported. ${ }^{30}$ Biodistribution studies as determined by inductively coupled plasma analysis demonstrated minimal uptake in vital organs such as liver, and kidney whereas significant accumulation of gold was achieved in the tumor. Significant tumor growth inhibition was observed when mice were treated with Au-C225-Gem compared with its nontargeted counterpart. Au-C225-Gem inhibited tumor growth significantly $(\sim 80 \%)$ compared with all other nontargeted groups Polymers/ nanomaterials.

Silver nanoparticles fabricated from aqueous leaf extract of mistletoe Dendrophthoe falcata (L.f) Ettingsh and have been established for its anticancer effect against human breast cancer (MCF-7) cells. ${ }^{31}$ Briefly, aqueous solution of $1 \mathrm{mM}$ $\mathrm{AgNO}_{3}$ was incubated with aqueous leaf extract at different temperatures in the range of $37^{\circ} \mathrm{C}-100^{\circ} \mathrm{C}$. The reaction mixtures were monitored spectrophotometrically by change in their colour of the reaction mixture during temperature treatment. FESEM showed spherical particles with size range between 5 to $45 \mathrm{~nm}$ with the average of $18.92 \mathrm{~nm}$. IC50 for MCF-7 cells was found to be $5 \mu \mathrm{g} / \mathrm{ml}$ of AgNPs as deduced from the MTT assay. Colloidal AgNPs with the plant bio compound on its surface showed greater cytotoxicity even at low dose as compared to the leaf extract. It could thus be concluded that colloidal AgNPs significantly enhanced the plants bioactivity.

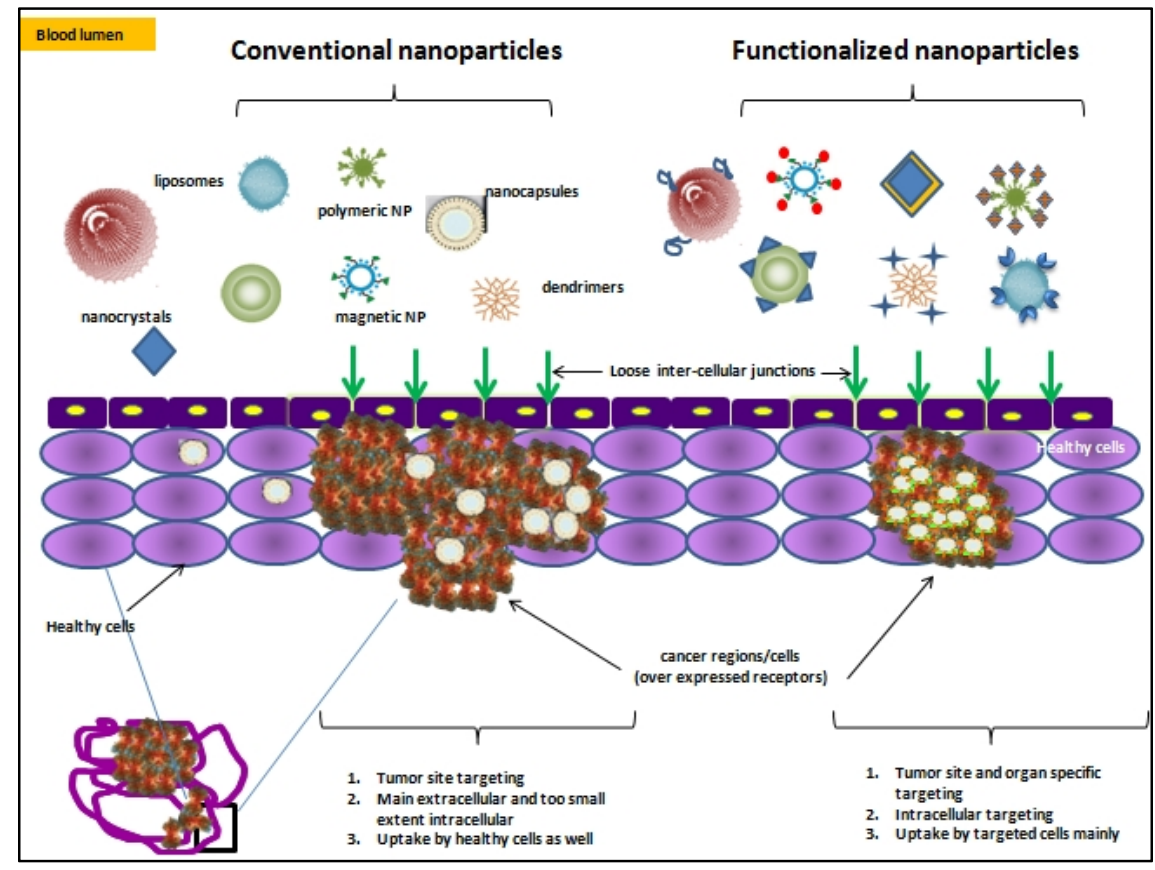

FIG. 2: Fate of conventional and surface modified nanoparticles in systemic circulation. 
Copper oxide nanoparticles $\mathrm{CuONPs}$ have generated great interest in the scientific community due to their high redox cycling and cytotoxicity on different cells via oxidative stress. ${ }^{32}$ Synthetic CuONPs (30 nm) were prepared by boiling of copper acetate along with acetic acid and $\mathrm{NaOH}$. Cytotoxicity of the synthesized nanoparticles was evaluated on human breast cancer cell line MCF7. CuO NPs treated in the presence of 3-MA, reduced the amount of cells undergoing autophagy in a time dependent manner. CuO NPs induced in vitro growth inhibition and autophagy in MCF7 cells. This approach may be an effective therapeutic strategy, in general, to sensitize chemoresistant cancer cells.

Superparamagnetic iron oxide nanoparticles are used in biomedical research for their unique magnetic properties, non-toxicity, and biocompatibility. The photo thermal effect of $\mathrm{Fe}_{3} \mathrm{O}_{4} /$ alumina ${ }^{33}$ and $\mathrm{Fe}_{3} \mathrm{O}_{4} / \mathrm{mSiO}_{2}{ }^{34}$ coreshell nanoparticles for killing bacteria and $\mathrm{KB}$ cancer cells has been recently reported. Spherical $\mathrm{Fe}_{3} \mathrm{O}_{4}$ nanoparticles $(9.1 \pm 1.9 \mathrm{~nm})$ were synthesized by co-precipitation of iron chloride salts with ammonia. $^{35}$ In vitro photothermal activity was tested on human oesophagus carcinoma cells (Eca-109) where the cells were grown in RPMI medium and irradiated with the 808 $\mathrm{nm}$ laser for 3, 15 and $20 \mathrm{~min}$ and continuously incubated at $37^{\circ} \mathrm{C}$ and cells observed under confocal microscope. The cells were shrunken implying that the cells incubated with magnetic nanoparticles were damaged or killed after 20 minutes of laser radiation. Quantitative cell cytotoxicity assay determined by the Cell Titer-Glo luminescent cell viability, showed that the Eca-109 cell viability significantly decreased to $52.16 \pm 12.30 \%$ after the cells were incubated with iron oxide nanoparticles containing $0.5 \mathrm{mg} / \mathrm{mL}$ of spherical $\mathrm{Fe}_{3} \mathrm{O}_{4}$ cores and $20 \mathrm{~min} 808 \mathrm{~nm}$ laser irradiated and continuously incubated at $37^{\circ} \mathrm{C}$ for $60 \mathrm{~min}$. To study the in vivo activity Eca-109 tumor-bearing mice were injected with PBS-dispersed with iron oxide nanoparticles $\left(\mathrm{Fe}_{3} \mathrm{O}_{4}: 8\right.$ $\mathrm{mg} / \mathrm{mL}$ ). The results showed $99.98 \pm 32.72 \%, 79.17 \pm 8.84 \%$, and $74.49 \pm 8.46 \%$ of $\mathrm{Fe}_{3} \mathrm{O}_{4}$ nanoparticles sustained in the tumors for 1, 3 and 24 days post-injection. This long term $\mathrm{Fe}_{3} \mathrm{O}_{4}$ uptake is particularly important for photothermal cancer therapies as the irradiation period normally lasts for at least three weeks.

\section{Mesoporous silica nanoparticles}

Mesoporous silica is a form of silica and a recent development in nanotechnology. The large surface area of the pores allows the particles to be filled with drug and be taken up by certain biological cells through endocytosis, depending on what chemicals are attached to the outside of the spheres. Some types of cancer cells will take up more of the particles than healthy cells will, giving researchers hope that mesoporous silica nanoparticles will be used to treat certain types of cancer. Mesoporous silica nanoparticles supported with synthetic dual-functional polymer-lipid material, P123-DOPE (PLS-MSNs), to facilitate intracellular delivery of anticancer drug and enhance the antitumor efficacy against MDR breast cancer cells have been synthesized. ${ }^{36}$ The membrane acted as an intact barrier for encapsulated drugs before reaching the target cells, leading to depolymerization and triggered storm release of loaded irinotecan (CPT-11) in acidic endosomal $\mathrm{pH}$ of tumor cells. P123-DOPE also inhibited breast cancer resistance protein (BCPR) mediated CPT-11 efflux in drug resistant MCF-7/BCRP breast cancer cells. Compared to free CPT-11, PLS-MSNs resulted in 12.9-fold increase in the intracellular CPT-11 concentration, had 7.1-fold higher cytotoxicity and processed a stronger cell cycle arrest in MCF- 7/BCRP cells. Moreover, CPT-11 loaded PLS-MSNs showed inhibition rate of $81.2 \%$ and low toxicity in BALB/c nude mice bearing drug resistant breast tumors. The PLS-MSNs thus provide promising applicability in future preclinical and clinical MDR cancer treatment.

\section{Chain Nanoparticles}

Treatment of micro metastases is impeded by several bio barriers, including their small size and high dispersion to organs, making them nearly inaccessible to drugs. To circumvent these limitations in treating metastatic disease, a multicomponent, flexible chain-like nanoparticle (termed nanochain) that possesses a unique ability to gain access to and be deposited at micro-metastatic sites have been developed. Moreover, coupling nanochain particles to radiofrequency (RF) triggered cargo delivery facilitated widespread delivery of drug into metastatic lesions. Peiris et al., have prepared multicomponent nanochain (nChain), comprising of three iron oxide (IO) nanospheres and one drug-loaded liposome chemically linked into a linear, chain-like assembly. ${ }^{37}$ The application of RF trigger on nChain-treated animals, resulted in eradication of metastatic disease. Due to the highly selective deposition of the nChain particles at metastases and efficient spreading of drug, significant therapeutic outcome was achieved at a low dose $(0.5 \mathrm{mg} / \mathrm{kg}), 10-20$-fold lower than the typical clinical regimens of liposomal Dox. ${ }^{38}$, 39 Thus, both the particle shape and the multicomponent nature of the nChain played an essential role in its therapeutic efficacy.

\section{Nanocrystals}

Nanocrystals, another industrially feasible technology ${ }^{40}$ is dealing with challenges of solubility and bioavailability associated with anticancer drugs. Number of targeted drug delivery systems for anticancer drugs are in market and many more are in research phase. Most of the nanocrystal production methods used achieved poor drug loading, variation in composition, attachment of targeting ligands to carriers, and in vivo and in vitro cellular uptake in cancer cell. Nanocrystals are now gaining attention from researchers and formulation scientists due to the ability to have better control saving cost, material, and time. 
Polyaspartic acid (PAsp) nanoparticles containing iron oxide nanocrystals and Dox have been prepared for cancer diagnosis and therapy. ${ }^{41}$ Iron oxide nanocrystals synthesized by the thermal decomposition method were incorporated into PAsp nanoparticles through an emulsion method. Dox, was incorporated into the PAsp nanoparticles via a solvent diffusion method for cancer therapy application. Superparamagnetic iron oxide nanocrystals $(6.01 \pm 1.67 \mathrm{~nm})$ were synthesized by a thermal decomposition method. The hydrophobic core of poly (aspartic acid) self-aggregates encapsulated the hydrophobic iron oxide nanocrystals via the oil-in-water emulsion method to obtain MPAN. A hydrophobic drug, Dox, was incorporated into a MPAN using solvent diffusion method to obtain MPAN (Dox) in the size range of $30-90 \mathrm{~nm}$. Cytotoxicity of SKBR-3 cells treated with the MPAN and MPAN (Dox) as determined by a MTT assay. MPAN were non-toxic and biocompatible and hence retained high cell viability whereas cytotoxic potency for the MPAN (Dox) was increased, which is attributed to successful delivery of Dox into the nuclei of cancer cells.

\section{Hydrogels}

Hydrogel is a network of polymer chains that are hydrophilic, sometimes found as a colloidal gel in which water is the dispersion medium. Hydrogels are highly absorbent (they can contain over $90 \%$ water) natural or synthetic polymeric networks. Hydrogels show flexibility very similar to natural tissue, due to their significant water content. Docetaxel (DTX) was encapsuled in micelles $(20 \mathrm{~nm})$ based on amphiphilic poly (3-caprolactone) epoly (ethylene glycol) epoly (3-caprolactone) copolymer to improve its solubility and permeability using thin-film hydration method. ${ }^{42}$ Methoxyl poly (ethylene glycol) epoly (3- caprolactone) eacryloyl chloride (PECA), poly (ethylene glycol) methyl ether methacrylate and itaconic acid (IA) were used as the co-monomers to synthesize the hydrogel with $\mathrm{pH}$ response properties. DTX micelles solution was completely absorbed in hydrogel owing to the swelling capability of hydrogel. Then the mixture was freeze-dried to obtain the stable DTX-micelle hydrogel system. The in vitro antiangiogenic activity was tested using MTT assay. The DTX micelles showed a lower $\mathrm{IC}_{50}$ value $(66.8 \mathrm{mg} / \mathrm{mL})$ thereby proving the improved cytotoxicity of DTX in micelles. Pharmacokinetic studies showed that the AUC for DTX micelles group was twice to that of Taxotere ${ }^{\mathrm{TM}}$ (31.2 versus $16.8 \mathrm{mg} / \mathrm{L}^{*} \mathrm{~h}$ ) with plasma half life $3.42 \mathrm{~h}$. The results proved that the clearance of DTX in plasma was prevented by polymeric micelles owing to the long-circulating effect of PEG.

The two crosslinked hydrogels, named HVa1 and HVa2, were synthesized by the free radical polymerization of vinyl monomers. The two hydrogels were loaded with platinum (II)-species using aqueous solution of cisplatin and temsirolimus. ${ }^{43}$ A zero-order release rate of platinum (II)-species was shown in $\mathrm{PBS}, \mathrm{pH} 7.4$, for more than one week. The loading of cisplatin and temsirolimus in DMF showed a two phase releasing pattern; the initial burst effect was always followed by the zero-order release rate for a week. Cytotoxicity testing was done on Me665/2/21 melanoma cell line which was close and in some cases higher compared to the native cisplatin at the same concentration; an interesting synergy in term of cytotoxicity was observed when a combined treatment of temsirolimus and cisplatin was used. The design of dual-stimuli-responsive hydrogels has opened an arena of developing biomaterials that can provide vehicles for the controlled release of actives under defined conditions.

\section{Chemotherapy wafers}

Wafer implants are used in the treatment of brain tumor treatment. The wafer is made of gel that contains a chemotherapy drug. Following surgical excision of the primary brain tumor, along the resection cavity, 6 - 8 chemotherapy wafers are placed. Over the next few days, the wafers slowly diffused the drug into the parenchyma over 2 to 3 weeks with peak release in week 1 , reaching local carmustine concentrations of $0.5-3.5 \mathrm{mM}$. Currently the wafers are licensed for people with either high grade malignant glioma or Glioblastoma multiform that has come back after treatment. The Gliadel ${ }^{\circledR}$ Wafer (MGI Pharma/Easai Pharmaceuticals), developed in the early 1980's by Langer and Brem, are the most-well studied and successful drug delivery implant for the treatment of recurrent brain cancer. The Gliadel ${ }^{\circledR}$ Wafers are dime-sized, biodegradable polyanhydride wafer containing carmustine and is used for the treatment of high grade malignant glioma. The polymer matrix is comprised of a copolymer of 1,3-bis-(p-carboxy phenoxy) propane and sebacic acid (PCPP-SA; 80:20 molar ratio) that is dissolved in an organic solvent with carmustine, spray-dried into microparticles ranging from $1-20 \mu \mathrm{m}$, and compression molded into wafers (14 $\mathrm{mm}$ diameter, $1 \mathrm{~mm}$ thick). The rigid wafers degrade in two-steps wherein water penetration hydrolyzes the anhydride bonds during the first 10 hours followed by erosion of the copolymer into the surrounding aqueous environment. The growth pattern of tumor recurrence in a clinical patients treated with Gliadel ${ }^{\circledR}$ Wafers has been studied. ${ }^{44}$ Almost $80 \%$ tumors that recurred were local or diffuse. Adequate carmustine levels were found up to $1 \mathrm{~cm}$ distant to the resection border with high concentration for carmustine. The improved survival rates of patients who received concomitant local and systemic adjuvant treatment with temozolomide (TMZ) support using local therapy to bridge the therapy-free interval of the initial postoperative phase.

\section{Carbon nanotubes}

Carbon nanotubes (CNTs) are rolled graphene sheets held together by van der Waals interactions. ${ }^{45}$ These interactions bundle CNTs together to form large aggregates. A single rolled layer of graphene forms a single-walled carbon nanotube (SWCNT, $0.4-2 \mathrm{~nm}){ }^{46}$ Multi-walled carbon nanotube 
(MWCNT, 2 - $100 \mathrm{~nm}$ ) have a length of a few microns, and an aspect ratio (L/D) of 1:1000. Large surface area of CNTs enables them to be conjugated, covalently or non-covalently with several biological molecules, like proteins, enzymes, nucleic acids and drugs. CNTs are produced by three major methods: electric arc discharge $(\mathrm{EAD})^{47}$, laser ablation $(\mathrm{LAB})^{48}$ and chemical vapour deposition (CVD). ${ }^{49}$ CNTs are generated from the vaporization of graphite targets $(\mathrm{EAD}$, LAB) or by passing a carbon containing vapour (e.g., CO) over supported metal catalyst nanoparticles in a furnace..$^{50}$

Individualized CNTs travel through various cellular barriers and even enter the nucleus, thus making them a drug carrier of choice for anti-tumor therapy. Ji et al. have constructed doxorubicin (Dox) loaded carbon nanotubes (CNTs). The CNTs were modified using chitosan (CHI) to allow water-solubility and biocompatibility to the nanotubes. ${ }^{51}$ Folic acid (FA) was coated onto the outer CHI layer to realize selective killing of tumor cells. The purified SWNTs were sonicated in CHI solution and stirred at room temperature. The modified SWNTs were washed with ultrapure water and dried at room temperature to obtain CHI/SWNTs. FA was attached to CHI/ SWNTs PBS buffer solution to obtain FA/CHI/SWNTs, using EDC-HCl as the coupling agent. Dox was introduced to $\mathrm{FA} / \mathrm{CHI} / \mathrm{SWNT}$ by stirring together for $16 \mathrm{~h}$ at room temperature to obtain Dox/FA/CHI/SWNTs.

The in vitro pharmaceutical efficiency of Dox/FA/CHI/SWNTs was evaluated on HCC cell line SMMC-7721, using the WST-1 assay. The viability of Dox/FA/CHI/SWNTs $(50 \mu \mathrm{g} / \mathrm{mL})$ treated cells showed a decline of $70 \%, 42 \%, 40 \%$ at 24,48 and 72 h respectively. In vivo efficacy tested on SMMC-7721 tumor bearing nude mice showed tumor growth inhibition of $21.7 \%$. Thus it was proved that Dox/FA/CHI/SWNTs killed the HCC SMMC-7721 cell lines and depressed the growth of liver cancer in nude mice, showing superior pharmaceutical efficiency to simple extracellular exposure or intravenous injection of the Dox itself.

In vivo cancer targeting potential of the Dox laden $\mathrm{D}$ - $\alpha$-tocopheryl polyethylene glycol 1000 succinate (vitamin E TPGS) tethered surface engineered MWCNTs nanoformulation (Dox/TPGS-MWCNTs) has been reported. ${ }^{52}$ Dox was dissolved in acetone and aqueous triethyl amine (TEA) solution was added in a molar ratio of 2:1 (Dox:TEA). The solution was magnetically stirred and mixed with the dispersion of MWCNTs in PBS (pH 7.4) to obtain Dox/ MWCNTs $(230.41 \pm 1.3 \mathrm{~nm})$ and Dox/TPGSMWCNTs (250.18 \pm 5.5 $\mathrm{nm})$. The in vivo tumor targeting efficacy was assayed on MCF-7 tumor bearing Balb/c model and the starting tumor size was $\sim 100 \mathrm{~mm}^{3}$. The size of the tumor volume $\left(\mathrm{mm}^{3}\right)$ was reduced to $85.9 \pm 2.92$ and $45.6 \pm 2.35$ on $30^{\text {th }}$ day after treatment with Dox/ MWCNTs and Dox/TPGS-MWCNTs formulations, respectively. These results confirmed the significant in tumor growth suppression of $\mathrm{D}$ - $\alpha$-tocopheryl polyethylene glycol 1000 succinate (vitamin E TPGS) tethered surface engineered MWCNTs.

A new flourishing area is graphene drug delivery; mainly being explored for cancer treatments. Lot of research is going on functionalized graphene to deliver anticancer drugs to affected organ. Graphene is a single layer of $\mathrm{sp}^{2}$ - hybridized carbon atoms arranged in a honeycomb two dimensional (2-D) crystal lattice. Due to its unique structure and geometry, graphene possesses remarkable physical-chemical properties, high fracture strength, and excellent electrical and thermal conductivity, fast mobility of charge carriers, large specific surface area and biocompatibility. Graphene and its composites have emerged as biosensors, nanocarriers for drug delivery and probes for cell and biological imaging. Integrin $\alpha_{V} \S_{3}$ mono-antibody functionalized graphene oxide (GO) complex nanocarriers (GO/PEI/PAH-Cit/Dox) have been developed for targeted delivery and controlled release of Dox into cancer cells. ${ }^{53}$ The cytotoxicity to the targeted cancer cells of various Dox loaded drug carriers was investigated using CCK- 8 assay. The in vitro release demonstrated that these nanocarriers effectively released Dox under mild acidic $\mathrm{pH}$ stimulation. Cellular toxicity assay, confocal laser scanning microscopy and flow cytometer analysis results together confirmed the selective transportation of Dox into the targeted cancer cells. Dox was found in the cytoplasm and moved into the nucleus subsequently. The effective delivery and release of the anticancer drugs into nucleus of the targeted cancer cells led to high therapeutic efficiency.

\section{Quantum dots (QD)}

Quantum dots are nanocrystals made of semiconductor materials that are small enough to exhibit quantum mechanical properties. Specifically, its excitons are confined in all three spatial dimensions. The electronic properties of these materials are intermediate between those of bulk semiconductors and of discrete molecules.

Multifunctional HER2 monoclonal antibody conjugated RNAs A-associated CdTe quantum dot cluster (HER2-RQDs) nanoprobes was prepared and its cytotoxicity was evaluated. ${ }^{54}$ HER2- RQDs nanoprobes could selectively kill gastric cancer MGC803 cells at $3 \mathrm{~h}$ post-injection, and in-situ gastric cancer cells at $6 \mathrm{~h}$ post-injection. Nanoprobes could inhibit the growth of gastric cancer tissues and extended survival time of cancer mouse models. High performance HER2-RQDs nanoprobes exhibited great potential in applications such as in-situ gastric cancer targeted imaging, and selective therapy. 
TABLE 2: List of ongoing clinical trials in the area of cancer therapies

\begin{tabular}{|c|c|c|c|}
\hline Name of the Study & Company/Sponsor & Status & Initiation year \\
\hline $\begin{array}{l}\text { Implementation of Electroporation - NanoKnife as } \\
\text { Treatment for Advanced Pancreatic Cancer }\end{array}$ & Aalborg University hospital & Phase 3 & 2014 \\
\hline $\begin{array}{l}\text { Targeted Atomic Nano-Generators (Actinium-225-Labeled } \\
\text { Humanized Anti-CD33 Monoclonal Antibody HuM195) in } \\
\text { Patients With Advanced Myeloid Malignancies }\end{array}$ & $\begin{array}{c}\text { Memorial } \\
\text { Sloan-Kettering Cancer Center }\end{array}$ & Phase 1 & 2014 \\
\hline $\begin{array}{l}\text { A Prospective Development Study Evaluating Focal } \\
\text { Therapy Using Irreversible Electroporation (Nanoknife }{ }^{\circledR} \text { ) in } \\
\text { Men With Localised Prostate Cancer }\end{array}$ & $\begin{array}{l}\text { University College London } \\
\text { Hospitals }\end{array}$ & Phase 1 & 2014 \\
\hline $\begin{array}{l}\text { PK and Safety of Paclitaxel Injection Concentrate for } \\
\text { Nano-dispersion alone and in Carboplatin Combination }\end{array}$ & $\begin{array}{l}\text { Sun Pharma Advanced Research } \\
\text { Company Limited }\end{array}$ & Phase 1 & 2013 \\
\hline $\begin{array}{l}\text { Pharmacokinetic (PK), Safety, and Tolerability Study of } \\
\text { Paclitaxel Injection Concentrate for Nano-dispersion } \\
\text { (PICN) Administered Weekly in Subjects With Advanced } \\
\text { Solid Malignancies in US Population }\end{array}$ & $\begin{array}{c}\text { Sun Pharma Advanced Research } \\
\text { Company Limited }\end{array}$ & Phase 1 & 2013 \\
\hline $\begin{array}{l}\text { Development of a Nanosecond Pulsed Electric Field System } \\
\text { to Treat Skin Cancer }\end{array}$ & $\begin{array}{c}\text { Children's Hospital \& Research } \\
\text { Center }\end{array}$ & Phase 1 & 2013 \\
\hline $\begin{array}{l}\text { Convection-Enhanced Delivery of Liposomal-Irinotecan } \\
\text { Using Real-Time Imaging With Gadolinium In Patients } \\
\text { With Recurrent High Grade Glioma }\end{array}$ & $\begin{array}{l}\text { University of California, San } \\
\text { Francisco }\end{array}$ & Phase 1 & 2013 \\
\hline $\begin{array}{l}\text { Clinical Study of the Antibacterial Properties of the Nano } \\
\text { Particles Which Incorporated With the Soft Liner Silicone - } \\
\text { in Obturators }\end{array}$ & Hadassah Medical Organization & Phase 1 & 2009 \\
\hline
\end{tabular}

TABLE 3: List of approved patents in area of cancer nanotherapeutics

\begin{tabular}{|c|c|c|c|c|}
\hline Year & Patent No. & Title & Objective & Applicant \\
\hline 2014 & US8785371 & $\begin{array}{l}\text { Drug delivery of te- } \\
\text { mozolomide for systemic } \\
\text { based treatment of cancer }\end{array}$ & $\begin{array}{l}\text { Preparation of a multifunctional nanoconjugate of temozolomide } \\
\text { (TMZ) conjugated to a polymalic acid platform which is further } \\
\text { conjugated to a monoclonal antibody to transferrin receptor, a } \\
\text { trileucine (LLL) moiety, and/or a polyethylene glycol (PEG) moiety. }\end{array}$ & Patil R, et al. \\
\hline 2014 & $\begin{array}{l}\text { EU-WO2014036555 } \\
\text { (A1) }\end{array}$ & $\begin{array}{l}\text { Drug delivery systems } \\
\text { and methods for treat- } \\
\text { ment of bladder cancer } \\
\text { comprising oxaliplatin }\end{array}$ & $\begin{array}{l}\text { Methods and devices for oxaliplatin delivery into the bladder from } \\
\text { an intravesical drug delivery device inserted into the bladder, } \\
\text { wherein the device continuously releases the oxaliplatin into the } \\
\text { urine in the bladder over an extended time. }\end{array}$ & $\begin{array}{l}\text { Taris biomedical } \\
\text { Inc. }\end{array}$ \\
\hline 2013 & $\begin{array}{l}\text { EU-WO2013100869 } \\
\text { (A2) }\end{array}$ & $\begin{array}{l}\text { Lipid-based nanocarrier } \\
\text { systems for using cancer } \\
\text { treatment }\end{array}$ & $\begin{array}{l}\text { Patent describes a nanocarrier composition comprising a self micro } \\
\text { emulsifying drug delivery system. }\end{array}$ & $\begin{array}{l}\text { Guersoy reyhan } \\
\text { neslihan, Cevik } \\
\text { oezge }\end{array}$ \\
\hline 2011 & US2011287085 (A1) & $\begin{array}{l}\text { Liposomal Curcumin for } \\
\text { treatment of cancer }\end{array}$ & $\begin{array}{l}\text { The methods and compositions of the present invention employ } \\
\text { curcumin or its analogues encapsulated in a colloidal drug delivery } \\
\text { system, such as liposomes nanoparticles, nanocapsules, microparti- } \\
\text { cles or block copolymer micelles. }\end{array}$ & $\begin{array}{l}\text { Kurzrock R, Li } \\
\text { Lan, Mehta K, } \\
\text { Aggarwal B. }\end{array}$ \\
\hline 2002 & US6641833 & $\begin{array}{l}\text { Methods for treating } \\
\text { ovarian cancer, poly } \\
\text { (phosphoester) composi- } \\
\text { tions, and biodegradable } \\
\text { articles for same }\end{array}$ & $\begin{array}{l}\text { Biodegradable polymer compositions for ovarian cancer, wherein } \\
\text { the polymer compositions provide extended release of the antineo- } \\
\text { plastic agent (e.g. Paclitaxel) into the peritoneum of the subject. }\end{array}$ & Dang Wenbin \\
\hline
\end{tabular}


Fluorescent QDs used for biomedical imaging and diagnostics has attracted considerable attention over the past decade. Chu et al. have reported the therapeutic efficacy of the popularly used red/brown, brown or close to black CdTe and CdSe QDs. ${ }^{55}$ Upon $671 \mathrm{~nm}$ laser irradiation; these QDs rapidly converted light energy into heat, both in vitro and in vivo. The growth of mouse melanoma tumors injected with CdTe (710) QDs coated with a silica shell $\left(\mathrm{SiO}_{2}\right)$ was significantly inhibited after laser irradiation, with eventual disappearance of the tumor. In contrast, tumors injected with the silica-coated QDs without subsequent irradiation continued to grow over time. They had a growth rate close to that of tumors injected with $\mathrm{SiO}_{2}$ or phosphate-buffered saline, with or without laser irradiation. The CdTe and CdSe QDs thus have great potential in the treatment of cancer using photothermal therapy.

Tables 2 and $\mathbf{3}$ give overview of recently conducted clinical trials and approved patents in area of cancer nanotherapeutics. In addition to drug delivery systems, several therapies like the plasma treatment, photodynamic therapy and cell therapy are now being investigated for treatment of cancer.

\section{Plasma treatment}

Plasma is a partially ionized argon gas, containing electrons, positive/negative ions, radicals, excited molecules, energetic photons (UV), and generating transient electric field. Electrons present in non-thermal plasma are highly energetic, with a typical temperature above $10,000 \mathrm{~K}$, while ions and neutral species remain at room temperature. Use of cold atmospheric plasma (CAP) on tumor cells has been increasingly reported in the treatment of cancer. It has been shown in vitro, that CAP in low concentration was able to stop tumor cells growing, to induce cell death in higher concentrations and was more effective than some standard treatments including radiation and chemotherapy. Moreover, first results indicated that CAP seemed to be selective for cancer cells since it was more effective in tumor cells than in normal non-neoplastic cells.

CAP induced antitumor effect on U87 malignant glioma xenografts has been reported. ${ }^{56}$ The U87-MG glioma cell line is characterized by a high radio and chemoresistance, and is an adequate model to explore a significant antitumor effect. This heterotopically grafted cancer cell line represents hemispherical growth that is a well-suited configuration for treatment with plasma and allows an accurate following of tumor growth by caliper measurement. To follow tumor growth, tumor volume was determined every day with the standard technique accepted internationally. Antitumor effects were assessed by tumor volume measurement and bioluminescence imaging (BLI). Plasma treatment applied for 5 consecutive days showed a significant tumor volume decrease $(56 \%)$ in treated mice and a concomitant decrease of BLI intensity. Also, there was $60 \%$ increase in mouse life span. This study showed a marked antitumor effect of plasma treatment in U87 glioma xenografts highlighting the potential of plasma treatment as an anticancer treatment with little or no toxic side effects.

\section{Stem cells}

Cancer stem cells (CSCs) are used in a variety of human cancers. CSCs possess the ability of self-renewal, metastasis and resistance to drug treatment, hence, the concept of CSCs targeting provides novel strategies for the prevention of tumor recurrence and for optimizing treatment. ${ }^{57,58}$ Since current conventional chemotherapy and radiotherapy are largely ineffective in depleting CSCs, a novel therapeutic strategy is urgently needed to specifically target CSCs for tumor eradication and to improve the survival of cancer patients. Since aberrant reactivation of the multiple signalling pathways including Hedgehog, Notch and $\mathrm{Wnt}^{59}$ are involved in the formation of CSCs, the chemotherapeutic agents that inhibit these pathways have emerged as promising therapeutic drugs for pancreatic cancer (PC). ${ }^{60} \mathrm{Up}$ - regulation of Hedgehog pathway promotes cell growth in PC, suggesting that Hedgehog inhibitors could be promising therapeutic drugs for PC. Studies have shown that the Hedgehog inhibitor cyclopamine, a naturally occurring antagonist of the Hedgehog signalling pathway component smoothened, can abrogate pancreatic cancer metastasis. ${ }^{61} \mathrm{It}$ has been reported that breast CSC number was reduced when Hedgehog activity is suppressed by cyclopamine, suggesting that Hedgehog pathway is essential for the proliferation of breast CSCs. ${ }^{62}$ Cyclopamine reduced the percentage of cells expressing the pancreatic cancer stem cell marker $\mathrm{ALDH}^{63}$, suggesting that pharmacologic Hedgehog pathway inhibition could be a novel therapeutic strategy for the treatment of PC. As Notch signalling is activated through the activity of $\gamma$-secretase, inhibition of $\gamma$-secretase is a promising strategy for cancer therapy.

Multiple GSIs have been reported with decreased cell growth, increased apoptosis, reduced cell migration and invasion in a variety of human cancers including PC. ${ }^{64} \mathrm{mTOR}$ signalling pathway is aberrantly activated in various human malignancies and plays an important role in CSCs, using mTOR inhibitors to block mTOR activity could be a novel strategy to treat human cancers. Rapamycin and its analogs such as everolimus, temsirolimus and ridaforolimus have shown to be promising anti - tumor agents. Metformin has been shown to exert anti-tumor activity in human cancers such as breast cancer. Metformin up-regulated nine miRNAs including miR-26a, miR-192 and Let-7c in PC cells. ${ }^{65}$ HDAC inhibitors like SAHA (suberoyl anilide hydroxamic acid) restore histone acetylation which leads to the reactivation of aberrantly silenced genes. SAHA has been found to inhibit cell growth and induce apoptosis in many types of human cancers including PC. It has been reported that SAHA induced apoptosis, and suppressed cell growth through activa- 
tion of caspase-3, caspase-9, PPAR cleavage, cytochrome c release, and up-regulation of Fas and Faas ligand expression in head and neck squamous cell carcinoma cells. ${ }^{66}$ Additionally, SAHA was found to be an effective radiosensitizer in colorectal carcinoma. ${ }^{67}$ Also, CXCR4 inhibitors like AMD3465 and AMD3100 have been reported against hematopoietic stem cells (HSCs).

The combination of DR5 (death receptor 5) agonistic monoclonal antibody with gemcitabine killed both pancreatic CSCs and tumor cells. ${ }^{68}$ Furthermore, salinomycin inhibited CSC growth, while gemcitabine suppressed non-CSC proliferation, suggesting that salinomycin combined with gemcitabine could be a promising therapeutic strategy to eradicate PC. ${ }^{69}$

\section{Epigenetic}

The epigenome (epi meaning above or beyond) consists of heritable modifications to histones and DNA which are independent of changes to the linear DNA sequence. Epigenetic modifications are dynamically established by DNA methyl transfereases (DNMTs), histone acetyl transfereases (HATs), histone methyl tranferases (HMTs), kinases, and removed or modified by histone deacetylases (HDACs), histone demethylases (HDMs), ten eleven translocation protein 1-3 (TET1-3), and phosphatases in a highly regulated manner. To date, four epigenetic drugs: 5-azacytidine (azacitidine or 5-aza-CR), 5-aza-20-deoxycytidine (5-aza-CdR or decitabine), vorinostat (suberoylanilide hydroxamic acid), and romidepsin have been approved by the US Food and Drug Administration (FDA). Azacidine and decitabine were approved for the treatment of high risk myelodysplastic syndrome, while vorinostat and romidepsin were approved for cutaneous $\mathrm{T}$ cell lymphoma (CTCL).

\section{Radiation therapy}

\section{Intensity modulated radiation therapy (IMRT)}

Radiotherapy (often abbreviated RT, RTx, or XRT) plays an important role in cancer therapy and covers cancer management upto $40 \%$ of cure rate. Radiation therapy is used to control or kill malignant cells and can be used to control or kill different types of cancer if they are localized to one area of the body. RT yields better functional outcomes when compared to surgery and thus is frequently used in conservative approaches. It may also be used as part of adjuvant therapy, to prevent tumor recurrence after surgery to remove a primary malignant tumor (for example, early stages of breast cancer). ${ }^{71}$

$\mathrm{X}$ rays are a form of electromagnetic radiation that delivers their energy through waves called photons. These photons are produced by accelerating a stream of electrons and colliding them with a metal target. High energy photons produce secondary electrons in human tissue. These electrons cause DNA damage which, if not repaired, proves fatal at cell division. Absorbed radiation doses are measured as $\mathrm{J} / \mathrm{kg}$, expressed in the unit gray (Gy). External beam radiotherapy (EBRT) usually uses high energy $\mathrm{X}$ rays, that penetrate deep into body tissue while relatively sparing the skin. Electrons can also be used for superficial treatments.

Vast advances have been made in the in the form of improvements in engineering and computing have enabled technologies such as intensity modulated radiotherapy (IMRT), image guided radiotherapy (IGRT), and stereotactic radiotherapy (SRT) to be used in routine clinical practice.

New RT technologies are emerging and the delivery of RT has evolved from two dimensional (2D-RT) techniques, based primarily on X-ray images and manual calculations, to 3D techniques, based on computerized tomography (CT) images incorporating progressively complex computer algorithms and modern hardware tools. ${ }^{70}$ The relationship between the patient's tumor and normal anatomy of the organ is used to deliver a radiation dose that conforms to the target volume and thus decreases exposure to other organs, defining the three-dimensional conformal radiation therapy (3DCRT). IMRT is an advanced form of 3D-CRT that utilizes non-uniform radiation beam intensities to increase the delivery of radiation to the planned treatment volume while minimizing irradiation of normal tissue outside the target. IMRT uses multiple beams with a highly non-uniform dose across the field. This is achieved by dividing the beam into multiple "beamlets," so that doses of varying intensity can be delivered to different parts of the field..$^{72}$

IMRT has the ability to reduce side effects, especially xerostomia $^{73}$, deliver treatments on complex tumoral targets with dose-escalation, while sparing organs at risk, especially salivary glands with no severe xerostomia at even after long term follow-up. ${ }^{74}$ IMRT is particularly useful for head and neck cancers due to the high number of important normal tissues in close proximity to the tumor. A phase III study using patients with squamous cell cancers of the oropharynx to conventional 3D-CRT or parotid sparing IMRT showed significant reduction in dry mouth after two years $(29 \% \mathrm{v}$ 83\%; $\mathrm{P}<0.0001$ ) with IMRT compared with 3D-CRT. ${ }^{75}$ IMRT uses multiple beams to deliver radiation to target site despite that normal tissue being spared higher doses, a greater volume of tissue receives a lower dose, thereby leading to an increased risk of cancer recurrence. ${ }^{76}$

\section{Image guided radiotherapy (IGRT)}

IGRT uses imaging just before radiotherapy and is delivered to allow positional correction if necessary so that the dose is correctly delivered to the target. ${ }^{77}$ This is done using CT imaging or by implanting radio-opaque seeds, that allow the target to be identified using treatment $\mathrm{X}$ rays. Accurate and specific treatment of the tumor is achieved and allows 
smaller safety margins to be used, thereby sparing healthy tissues. Image guidance is crucial to the use of IMRT because steep dose gradients carry a risk of the target being given too low a dose and normal tissue being overdosed.

In case of lung cancers, the tumors move with respiration and if this variation is great, four dimensional CT is used to obtain a series of CT scans at different phases of the respiratory cycle, which can then be targeted with respiratory gating. This involves tracking the patient's respiratory cycle, commonly using surface markers, and delivering treatment at specific phases of the cycle.

\section{Stereotactic radiotherapy (SRT)}

SRT is highly targeted specific treatment used to treat a variety of brain lesions, using traditional fractionations such as $60 \mathrm{~Gy}$ in 30 fractions. SRT is often administered using frame technique, although frameless techniques are also available. SRT can be delivered using several different machines such standard linear accelerators, which use multiple beams from different angles centred on the tumor, and the Gamma Knife, which is designed exclusively to treat intracranial lesions by surgical operations. Stereotactic ablative radiotherapy (SABR), also known as stereotactic body radiotherapy, involves precise irradiation of extracranial lesions. ${ }^{78}$ It is now increasingly used in the treatments of lung, prostate, liver, and pancreatic lesions. ${ }^{79}$ It can be delivered using a standard linear accelerator, equipped for image guided IMRT. For mobile lesions tracking or gating technology is used.

The CyberKnife is a frameless robotic system consisting of a linear accelerator mounted on a robotic arm. It delivers treatment with high accuracy and uses real time image guidance to track the tumor. To allow this, most tumors require implantation of metal markers leading to complications such as pneumothorax in case of lung cancers, but newer software is now being developed that can track some peripheral tumors without markers.

\section{Proton beam therapy}

Proton beam therapy is an established technology that uses protons to deliver the radiation dose. ${ }^{80,81}$ The physical properties of protons enable the dose to be deposited up to, but not beyond, a specific depth within tissue. This limited range of dose deposition allows improved target volume coverage, with reduced exposure to the normal tissues. ${ }^{81}$ This treatment is widely being used in the treatment of spinal and base of the skull tumors, prostate cancer especially in children and young adults.

\section{Vaccines}

Several complex key components of the immune response to tumors have been defined and studied in the recent years, with the cytotoxic $\mathrm{T}$ lymphocyte response being identified as a critical link among these components. Though immune system is associated with inhibition of tumor growth and progression, immune responses sometimes may also promote tumor cell growth and survival through induction of inflammation..$^{82}$ The key factor to the use of immune response system against tumors is that most tumor cells express antigens that are not found on normal cells. These tumor-associated antigens (TAAs) come from sources, including oncogenic viruses, expression of oncogenes or mutated oncosupressors, or expression of mutated genes. Vaccines based upon antigens ranging from recombinant subunit proteins to whole, inactivated cancer cells have been evaluated preclinically and clinically. ${ }^{83,84}$ Therapeutic cancer vaccines have been developed with whole, inactivated autologous or allogeneic cancer cells such as the GVAX vaccine which combines irradiated, cultured cancer cells as a treatment for pancreatic cancer. ${ }^{85}$ Dendritic cells harvested from patients are stimulated in vitro by pulsing with peptides or proteins have been used to treat prostate cancer, melanoma, and colorectal cancer. ${ }^{86}$ Peptides or proteins which are either TAAs or proteins associated with a key aspect of tumor progression as vaccine antigens, such as gp100 as an antigen in a therapeutic melanoma vaccine, ${ }^{87}$ anti-lymphoma antibody as an antigen in a therapeutic anti-idiotype lymphoma vaccine. ${ }^{88}$ Delivery of specific antigens to the immune system using recombinant vectors, including Poxvirus to deliver prostate specific antigen (PSA) as a prostate cancer vaccine, Listeria to deliver mesothelin as vaccine for pancreatic cancer, and adenovirus to deliver CEA as a vaccine for carcinoma.

\section{miRNA therapy}

MicroRNAs (miRNA) are small RNA molecules (19-25 nucleotides) and encoded in genomes of plants, animals, fungi and viruses. miRNAs are a highly conserved class of naturally occurring non-coding single-stranded RNA molecules, which function as post-transcriptional negative gene regulators of complementary target mRNAs. ${ }^{89}$ Although they may differ in distinct organisms, the basic process involves a transcription of RNA that is processed into shorter units that mediate target recognition in a sequence-specific manner. It is reported that around $74 \%$ and $92 \%$ of the gene transcripts are probably under control of miRNA. ${ }^{90}$ miRNAs play a crucial role in normal biological processes, such as cellular differentiation, proliferation and apoptosis through a complicated gene regulation networking..$^{91}$ miRNAs control gene expression at a post-transcriptional level, either by degrading or blocking translation of messenger RNA target. Amplification or over expression of miRNAs can down-regulate tumor suppressors or other genes involved in cell differentiation, thereby contributing to tumor formation by stimulating proliferation, angiogenesis, and invasion; i.e., they act as oncogenes. Similarly, miRNAs can down-regulate different proteins with oncogenic activity; i.e., they act as tumor suppressors. In addition, it is now clear that each type 
of tissues present proper miRNAs expression levels; similarly, each tumor sub-/type presents a unique "miRNAs signature". This specificity explains the differences among cancer sub-/types, as well as primary and metastatic tumors. ${ }^{92}$

\section{Monoclonal antibodies}

The use of monoclonal antibodies has revolutionized both cancer therapy and cancer imaging. Antibodies have been used to directly inhibit tumor cell proliferation or to target drugs to tumors. Also in molecular imaging, monoclonal antibodies have found their way to the clinic. Nevertheless, distribution within tumors is hampered by their size, leading to insufficient efficacy of cancer treatment and irregular imaging. An attractive alternative for monoclonal antibodies are nanobodies or $\mathrm{VHHs}_{\mathrm{H}}$. These are the variable domain of heavy-chain antibodies from animals from the Camelidae family that were first discovered in 1993. Stimulated by the ease of nanobody selection, production, and low immunogenicity potential, a number of nanobodies specific to different disease related targets have been developed. For cantherapy, nanobodies have been employed as antagonistic drugs, and more recently, as targeting moieties of effector-domains and of drug delivery systems. In parallel, nanobodies have also been employed for molecular imaging with modalities such as nuclear and optical imaging. With a wide range of successful applications, nanobodies have become much more than simple antagonists. First anti-tumor mAb, rituximab (Rituxan ${ }^{\circledR}$ ), was approved in 1997 for clinical use. Trastuzumab, Cetuximab and several other antibodies are now widely recognised as therapeutic molecules. However none of them are able to cure cancer as single agents. Several clinical outcomes and animal studies have highlighted major limitations in their modes of action, including redundancy of molecular pathways leading to cancer cell survival, effects of the microenvironment, suboptimal interaction with effector cells due to alternative Fc glycosylation or Fc receptor polymorphism, activation of inhibitory receptors, and competition with circulating IgG. Several studies are going on for overcoming these drawbacks.

Biospecific antibodies (Triomabs ${ }^{\circledR}$ ) using mouse IgG2a and IgG2b have been reported. ${ }^{93}$ They demonstrated a preferential species-restricted heavy/light chain pairing and use of sequential $\mathrm{pH}$ elution on protein $\mathrm{A}$ to easily separate the desired $\mathrm{bsAb}$ from the parental $\mathrm{mAb}$. The resulting hybrid rat/mouse Fc portion efficiently interacted with activating human $F_{c}$ receptors (FcyRI and FcyRIII), but not inhibitory ones (FcyRIIB). The investigators also created an anti-CD3 $\times$ anti-EpCAM bsAb, and demonstrated that this antibody was capable of binding to target cells and human T cells, but was also capable of activating dendritic cells (DC), inducing NK-dependent ADCC and stimulating tumor cell phagocytosis by macrophages. Catumaxomab, which targets the tumor antigen EpCAM, was the first Triomabs produced. EpCAM (CD326) is expressed on essentially all human adenocarci- noma, certain squamous cell carcinoma, retinoblastoma and hepatocellular carcinoma. In vitro and in vivo preclinical demonstrated that Catumaxomab was able to kill tumor cells very efficiently, at low concentration (10 pM range). In animal studies, mice injected with $4 \mu \mathrm{g}$ of triomabs survived intraperitoneal injection of a lethal dose of Ep$\mathrm{CAM}^{+}$melanoma cells. Moreover, initial treatment of the tumor led to total tumor eradication and induced immune protection. In a Phase $1 / 2$ clinical trial, ovarian cancer patients with malignant ascites were treated with Catumaxomab ( 4 to 5 doses of 5 to $200 \mu \mathrm{g}$ ) did not require paracenbetween the last infusion and the end of study at day 37 . Tumor cell monitoring revealed a reduction of EpCAM-positive malignant cells in ascites by up to $5 \mathrm{log}$ and a four-fold increase in puncture-free survival compared to those receiving paracentesis therapy only.

\section{Personalized treatment}

Standard therapy inevitably fails in many patients as it ignores the heterogeneity of tumor response to drugs. Viable cellular chemosensitivity assay triggered the development of personalized treatment for tumors. ATP-based chemosensitivity assay was developed in the early 1990s to evaluate the new drugs and combinations, to understand the molecular basis of drug resistance and sensitivity to anti-cancer drugs. Fragments of tumor from fresh tumor resection specimens or biopsies obtained directly from the operating theatre are used. The fragments are incubated with collagenase based medium resulting in a suspension of single cells, and plated 20,000 cells per well. Drugs are added and the plates of incubated for six days at $37^{\circ} \mathrm{C}$ in a $\mathrm{CO}_{2}$ incubator. The cells are then extracted and ATP content measured by luciferin-luciferase assay. The ATP-TCA is very useful test for drug development, allowing early testing of compounds against different cancer types and is helpful for the in vitro design of new combinations. The assay also indicates the level of heterogeneity present between patients in terms of their response to new and old drugs. Recent developments have allowed genotyping and phenotyping of tumors, providing a plethora of targets for the development of new cancer treatments. However, validation of such targets and new agents permit translation to the clinic is difficult. The ATP-TCA similar assays assess all pharmacodynamic mechanisms at once, provide tumor derived cells to test new drugs, allow design of new combinations, and allow mechanistic studies resistance and sensitivity to new or old agents. Their major disadvantage is that they need a high quantity of fresh tumor tissue. The use of molecular methods to obtain sensitivity from tumor tissue is done by DNA or RNA formalin-fixed paraffin embedded (FFPE) tissue blocks stored following diagnosis. Sequencing of target genes, or whole exome/genome sequencing, can be used to define the genetics of individual tumors. ${ }^{94}$ Quantitative reverse transcriptase polymerase chain reaction (qRT-PCR) can be used to define expression accurately ${ }^{95,96}$ or whole genome (e.g. Affymetrix) 
arrays. Since most drugs hit proteins, their expression and function, can be assessed directly by Western blots and immunocytochemistry. Thus, cell line and primary cell cultures permit the molecular investigation of sensitivity and resistance in a way that is difficult to achieve from clinical and can predict the response to patients to anti-cancer Molecular data can predict the sensitivity of cancer cells to new agents, the challenge being use of the molecular understanding with limited cellular assay information to improve both drug development and the design of companion diagnostics to guide their use.

\section{Advances in diagnosis and imaging techniques}

Leading pharma and biotech companies are working in several directions to treat cancer. Cantilevers are designed to detect early molecular events in mutagenesis. On the other hand nanopores can act as decoders for DNA sequencing information; this can help to find mutations in the DNA and can be linked to type of cancer in early stage.

\section{Herbal remedies}

Main success of herbal therapies lies in trust of physician's generations in using indigenous systems of medicine for over hundreds of years. Mainly plants with potent antioxidant property are researched for anticancer properties. Lycopene, Curcumin, Apigenin and many more are studied for prevention of certain malignancies, especially prostate cancer. The development of biocompatible nanoparticles, enhanced solubilities with reduced drug doses in new nanotechnological form are thereby exhibiting very good targeting profiles in vivo. TCM, Ayurveda are some leading treatment areas that show no added toxicity, even at molecular level, and are of considerable interest for future research. New areas like SiRNA, graphene and herbal medicine are now rapidly developing for fight against cancer.

\section{Conclusion}

Advancement in cancer research and therapies is fastened by possibilities of record breaking technologies and its applications. Lot of limitations like drug properties, industrial scale up and stability still hinder the path of drug candidates to clinical trial. However, collaboration of clinicians with research scientist, chemist, and academia is adding value to the new research developments. This overview of drug delivery systems and treatments clearly shows that lot of research has been done in this direction and can be proved by the presence of number of drug candidates in clinical trials. Nanoparticles are definitely an ideal drug delivery system which offers numerous advantages over conventional dosage forms and can direct drug to specific site or organ in body. Other therapies like radiation, phototherapy, and siRNA delivery are advancing rapidly and studied widely.

\section{Conflict of interest}

The authors declare that they have no conflicts of interest. The authors alone are responsible for the content and writing of the paper.

\section{List of Abbreviations}

TCM: Traditional Chinese Medicine

IARC: International agency for research on cancer

SLNs: Solid Lipid Nanoparticles;

NLCs: Nano Lipid Carriers

Dox: Doxorubicin; DCX: Docetaxel

PS: Particle size; PDI: Polydispersity Index; ZP: Zeta Potential

ATRA: All-trans retinoic acid

PONC: Polymer-oil nanostructured carriers

DMPC: Dimyristoyl phosphatidylcholine;

DMPG: Dimyristoyl phosphatidylglycerol

PEG: Polyethylene glycol; PGA: Polyglutamic acid

WGA: Wheat germ agglutinin

SMVT: Sodium dependent multivitamin transporter

SPR: Surface plasmon resonance

EGFR: Epidermal growth factor receptor

FESEM: Field emission scanning electron microscopy

MTT: 3-(4, 5-Dimethylthiazol-2-yl)-2, 5- diphenyltetrazolium bromide

PAsp: Polyaspartic acid

PECA: Methoxyl poly (ethylene glycol) epoly (3- caprolactone)eacryloyl chloride

MPEGMA: Poly (ethylene glycol) methyl ether methacrylate IA: Itaconic acid

CNT: Carbon nanotube; SWCNT: single - walled carbon nanotube; MWCNT: Multiple - walled carbon nanotube

EAD: Electric arc discharge ; LAB: Laser ablation

CVD: Chemical vapour deposition

CAP: Cold atmospheric plasma

BLI: Bioluminescence imaging

DNMTs: DNA methyltransfereases

HATs: Histone acetyltranferases

HMTs: Histone methyltranferases

HDACs: Histone deacetylases

HDMs: Histone demethylases

TET1-3: Ten eleven translocation protein 1-3

CCK assay: Cell Counting Kit assay

qRT -PCR: Quantitative reverse transcriptase Polymerase

Chain Reaction

Dox : Doxorubicin

\section{References}

1. IARC Press release, 2013. Available from http://ci5.iarc.fr/ [Accessed on May 02, 2014]

2. Stortecky S, Suter TM. Insights into cardiovascular side-effects of modern anticancer therapeutics. Curr Opin Oncol 2010; 22:312-7. 
3. Wang X, Yang L, Chen ZG, Shin DM. Application of nanotechnology in cancer therapy and imaging. CA Cancer J Clin 2008; 58:97-110.

4. Aznar MA, Lasa-Saracíbar B, Estella-Hermoso de Mendoza A, Blanco-Prieto MJ. Efficacy of edelfosine lipid nanoparticles in breast cancer cells. Int J Pharm 2013; 454:720-6.

5. Kang KW, Chun MK, Kim O, et al. Doxorubicin-loaded solid lipid nanoparticles to overcome multidrug resistance in cancer therapy. Nanomedicine 2010; 6:210-3.

6. Narvekar M, Xue HY, Tran NT, et al. A new nanostructured carrier design including oil to enhance the pharmaceutical properties of retinoid therapy and its therapeutic effects on chemo-resistant ovarian cancer. Eur J Pharm Biopharm 2014; 88:226-37.

7. Siddikuzzaman, Guruvayoorappan C, Berlin Grace VM. All trans retinoic acid and cancer. Immunopharmacol Immunotoxicol 2011; 33:241-9.

8. Chang HI, Yeh MK. Clinical development of liposome-based drugs: formulation, characterization, and therapeutic efficacy. Int J Nanomedicine 2012; 7:49-60.

9. Jantscheff $\mathrm{P}$, Ziroli $\mathrm{V}$, Esser $\mathrm{N}$, et al. Anti-metastatic effects of liposomal gemcitabine in a human orthotopic LNCaP prostate cancer xenograft model. Clin Exp Metastasis 2009; 26:981-92.

10. Jantscheff P, Esser N, Graeser R, et al. Liposomal gemcitabine (GemLip)-efficient drug against hormone-refractory Du145 and PC-3 prostate cancer xenografts. Prostate 2009; 69:1151-63.

11. Crom WR, de Graaf SS, Synold T, et al. Pharmacokinetics of vincristine in children and adolescents with acute lymphocytic leukemia. J Pediatr 1994; 125:642-9.

12. Boman NL, Tron VA, Bally MB, Cullis PR. Vincristine-induced dermal toxicity is significantly reduced when the drug is given in liposomes. Cancer Chemother Pharmacol 1996; 37:351-5.

13. Immordino ML, Dosio F, Cattel L. Stealth liposomes: review of the basic science, rationale, and clinical applications, existing and potential. Int $J$ Nanomedicine 2006; 1:297-315.

14. P Farrell N. Platinum formulations as anticancer drugs clinical and pre-clinical studies. Curr Top Med Chem 2011; 11:2623-31.

15. Lukyanov AN, Elbayoumi TA, Chakilam AR, Torchilin VP. Tumor-targeted liposomes: doxorubicin-loaded long-circulating liposomes modified with anti-cancer antibody. J Control Release 2004; 100:135-44.

16. Saul JM, Annapragada AV, Bellamkonda RV. A dual-ligand approach for enhancing targeting selectivity of therapeutic nanocarriers. J Control Release 2006; 114:277-87.
17. Chiu GN, Abraham SA, Ickenstein LM, et al. Encapsulation of doxorubicin into thermosensitive liposomes via complexation with the transition metal manganese. J Control Release 2005; 104:271-88.

18. Wagner A, Vorauer-Uhl K. Liposome technology for industrial purposes. J Drug Deliv 2011; 2011:591325.

19. Al-Ahmady ZS, Al-Jamal WT, Bossche JV, et al. Lipid-peptide vesicle nanoscale hybrids for triggered drug release by mild hyperthermia in vitro and in vivo. ACS Nano 2012; 6:9335-46.

20. Lollo G, Rivera-Rodriguez GR, Bejaud J, et al. Polyglutamic acid-PEG nanocapsules as long circulating carriers for the delivery of docetaxel. Eur $J$ Pharm Biopharm 2014; 87:47-54.

21. Mohamed F, van der Walle CF. Engineering biodegradable polyester particles with specific drug targeting and drug release properties. J Pharm Sci 2008; 97:71-87.

22. Chen HM, Langer R. Oral particulate delivery: status and future trends. Adv Drug Del 1998; 34:339-50.

23. Kim GJ, Nie S. Targeted Cancer Nanotherapy. Materials Today 2005; 8:28-33.

24. Heinrich EL, Welty LA, Banner LR, Oppenheimer SB. Direct targeting of cancer cells: a multiparameter approach. Acta Histochem 2005; 107:335-44.

25. Wang C, Ho PC, Lim LY. Wheat germ agglutinin-conjugated PLGA nanoparticles for enhanced intracellular delivery of paclitaxel to colon cancer cells. Int J Pharm 2010; 400:201-10.

26. Lesniak MS, Upadhyay U, Goodwin R, Tyler B, Brem H. Local delivery of doxorubicin for the treatment of malignant brain tumors in rats. Anticancer Res 2005; 25:3825-31.

27. Tian X, Yin H, Zhang S, et al. Bufalin loaded biotinylated chitosan nanoparticles: an efficient drug delivery system for targeted chemotherapy against breast carcinoma. Eur J Pharm Biopharm 2014; 87:445-53.

28. Patra CR, Bhattacharya R, Mukhopadhyay D, Mukherjee P. Application of gold nanoparticles for targeted therapy in cancer. J Biomed Nanotechnol 2008; 4: 99-132.

29. Mukherjee $\mathrm{P}$, Bhattacharya $\mathrm{R}$, Patra $\mathrm{CR}$, et al. Nanogold in Cancer Therapy and Diagnosis. Chapter 3, Wiley-VCH, Weinheim, Germany, 2007; 7.

30. Patra CR, Bhattacharya R, Mukhopadhyay D, Mukherjee P. Fabrication of gold nanoparticles for targeted therapy in pancreatic cancer. Adv Drug Deliv Rev 2010; 62:346-61.

31. Sathishkumar G, Gobinath C, Wilson A, Sivaramakrishnan S. Dendrophthoe falcata (L.f) Ettingsh (Neem mistletoe): a potent bioresource to fabricate silver nanoparticles for anticancer effect against 
human breast cancer cells (MCF-7). Spectrochim Acta A Mol Biomol Spectrosc 2014; 128:285-90.

32. Laha D, Pramanik A, Maity J, et al. Interplay between autophagy and apoptosis mediated by copper oxide nanoparticles in human breast cancer cells MCF7. Biochim Biophys Acta 2014; 1840:1-9.

33. Liu X, Tao H, Yang K, et al. Optimization of surface chemistry on single-walled carbon nanotubes for in vivo photothermal ablation of tumors. Biomaterials 2011; 32:144-51.

34. Liao MY, Lai PS, Yu HP, et al. Innovative ligand-assisted synthesis of NIR-activated iron oxide for cancer theranostics. Chem Commun (Camb) 2012; 48:5319-21.

35. Chu M, Shao Y, Peng J, et al. Near-infrared laser light mediated cancer therapy by photothermal effect of Fe3O4 magnetic nanoparticles. Biomaterials 2013; 34: $4078-88$.

36. Zhang X, Li F, Guo S, et al. Biofunctionalized polymer-lipid supported mesoporous silica nanoparticles for release of chemotherapeutics in multidrug resistant cancer cells. Biomaterials 2014; 35: 3650-65.

37. Peiris PM, Toy R, Abramowski A, et al. Treatment of cancer micrometastasis using a multicomponent chain-like nanoparticle. J Contr Rel 2014; 173: 51-8.

38. Gabizon A, Goren D, Horowitz AT, et al. Long-circulating liposomes for drug delivery in cancer therapy: a review of biodistribution studies in tumor-bearing animals. Adv Drug Deliv Rev 1997; 24: 337-44.

39. Rose PG. Pegylated liposomal doxorubicin: optimizing the dosing schedule in ovarian cancer. Oncologist 2005; 10: 205-14.

40. Shegokar R, Muller RH. Nanocrystals: Industrially feasible multifunctional formulation technology for poorly soluble actives. Int $J$ Pharm 2010; 399: 129-39.

41. Yang HM, Oh BC, Kim JH, et al. Multifunctional poly(aspartic acid) nanoparticles containing iron oxide nanocrystals and doxorubicin for simultaneous cancer diagnosis and therapy. Colloids Surf $A$ Physicochem Eng Asp 2011; 391:208-15.

42. Wang Y, Chen L, Tan L, et al. Biomaterials 2014, -Forthcoming in 2014. Available from http://dx.doi.org/10.1016/j.biomaterials.2014.04.099

43. Casolaro M, Del Bello B, Maellaro E. Hydrogel containing L-valine residues as a platform for cisplatin chemotherapy. Colloids Surf B Biointerfaces 2011; 88:389-95.

44. Dörner L, Mustafa A, Rohr A, et al. Growth pattern of tumor recurrence following bischloroethylnitrosourea (BCNU) wafer implantation in malignant glioma. JClin Neurosci 2013; 20: 429-34.
45. Dolatabadi J, Omidi Y, Losic D. Carbon nanotubes as an advanced drug and gene delivery nanosystem. Curr Nanosci 2011; 7:297-314.

46. Iijima S. Carbon nanotubes: past, present, and future. Phys B Condens Matter 2002; 323:1-5.

47. Journet C, Maser WK, Bernier P, et al. Large-scale production of single-walled carbon nanotubes by the electric-arc technique. Nature 1997; 388 :756-8.

48. Scott CD, Arepalli S, Nikolaev P, Smalley RE. Growth mechanisms for single-wall carbon nanotubes in a laser-ablation process. Appl Phys A Mater Sci Process 2001; 72:573-80.

49. Huang ZP, Wu JW, Ren ZF, et al. Growth of highly oriented carbon nanotubes by plasma-enhanced hot filament chemical vapour deposition. Appl Phys Lett 1998; 73:3845-7.

50. Seah CM, Chai SP, Mohamed AR. Synthesis of aligned carbon nanotubes. Carbon 2011; 49: 4613-35.

51. Ji Z, Lin G, Lu $\mathrm{Q}$ et al. Targeted therapy of SMMC-7721 liver cancer in vitro and in vivo with carbon nanotubes based drug delivery system. $J$ Colloid Interface Sci 2012; 365:143-9.

52. Mehra NK, Verma AK, Mishra PR, Jain NK. The cancer targeting potential of D-a-tocopheryl polyethylene glycol 1000 succinate tethered multi walled carbon nanotubes. Biomaterials 2014; 35: 4573 -88.

53. Zhou S, Hashida Y, Kawakami S, et al. Preparation of immunostimulatory single-walled carbon nanotube/CpG DNA complexes and evaluation of their potential in cancer immunotherapy. Int J Pharm 2014; 471:214-23.

54. Ruan J, Song H, Qian Q et al. HER2 monoclonal antibody conjugated RNase-A-associated CdTe quantum dots for targeted imaging and therapy of gastric cancer. Biomaterials 2012; 33: 7093-102.

55. Chu M, Pan X, Zhang D, et al. The therapeutic efficacy of CdTe and CdSe quantum dots for photothermal cancer therapy. Biomaterials 2012; 33: 7071- 83.

56. Vandamme M, Robert E, Dozias S, et al. Response of Human Glioma U87 Xenografted on Mice to Non Thermal Plasma Treatment. Plasma Med 2011; 1: 27-43.

57. Pietras A. Cancer stem cells in tumor heterogeneity. Adv Cancer Res 2011; 112:255-81.

58. Chen SY, Huang YC, Liu SP, Tsai FJ, Shyu WC, Lin SZ. An overview of concepts for cancer stem cells. Cell Transplant 2011; 20:113-20.

59. Takebe N, Harris PJ, Warren RQ, Ivy SP. Targeting cancer stem cells by inhibiting Wnt, Notch, and Hedgehog pathways. Nat Rev Clin Oncol 2011; 8: 97-106. 
60. Lauth M, Toftgard R. Hedgehog signaling and pancreatic tumor development. Adv Cancer Res 2011; 110:1-17.

61. Kelleher FC. Hedgehog signaling and therapeutics in pancreatic cancer. Carcinogenesis 2011; 32: 445-1.

62. Tanaka H, Nakamura M, Kameda C, et al. The Hedgehog signaling pathway plays an essential role in maintaining the CD44+CD24-/low subpopulation and the side population of breast cancer cells. Anticancer Res 2009; 29: 2147-57.

63. Feldmann G, Dhara S, Fendrich V, et al. Blockade of Hedgehog signaling inhibits pancreatic cancer invasion and metastases: a new paradigm for combination therapy in solid cancers. Cancer Res 2007; 67: 2187-96.

64. Li C, Wu JJ, Hynes $\mathrm{M}$, et al. c-Met is a marker of pancreatic cancer stem cells and therapeutic target. Gastroenterology. 2011; 141:2218-27.

65. Li W, Yuan Y, Huang L, et al. Metformin alters the expression profiles of microRNAs in human pancreatic cancer cells. Diabetes Res Clin Pract 2012; 96:187-95.

66. Gillenwater AM, Zhong M, Lotan R. Histone deacetylase inhibitor suberoylanilide hydroxamic acid induces apoptosis through both mitochondrial and Fas (Cd95) signaling in head and neck squamous carcinoma cells. Mol Cancer Ther 2007; 6:2967-75.

67. Folkvord S, Ree AH, Furre T, Halvorsen T, Flatmark K. Radiosensitization by SAHA in Experimental Colorectal Carcinoma Models-In vivo Effects and Relevance of Histone Acetylation Status. Int J Radiat Oncol Biol Phys 2009; 74: 546-552.

68. Rajeshkumar NV, Rasheed ZA, Garcia-Garcia E, et al. A combination of DR5 agonistic monoclonal antibody with gemcitabine targets pancreatic cancer stem cells and results in long-term disease control in human pancreatic cancer model. Mol Cancer Ther 2010; 9: 2582-92.

69. Zhang $\mathrm{M}, \mathrm{Ma} \mathrm{Q}, \mathrm{Hu} \mathrm{H}$, et al. Stem cell factor/c-kit signaling enhances invasion of pancreatic cancer cells via HIF-1alpha under normoxic condition. Cancer Lett. 2011; 303:108-17.

70. Tubiana M. The role of local treatment in the cure of cancer. Eur J Cancer 1992; 28A:2061-9.

71. Saha A, Chattopadhyay S. Assessment of pulmonary toxicities in breast cancer patients undergoing treatment with anthracycline and taxane based chemotherapy and radiotherapy- a prospective study. Int J Cancer Ther Oncol 2013; 1:01021.

72. Moorthy S, Sakr H, Hasan S, et al. Dosimetric study of SIB-IMRT versus SIB-3DCRT for breast cancer with breath-hold gated technique. Int $J$ Cancer Ther Oncol 2013;1:010110.
73. Dearnaley DP, Khoo VS, Norman AR, et al. Comparison of radiation side-effects of conformal and conventional radiotherapy in prostate cancer: a randomised trial. Lancet 1999; 353:267-72.

74. Chow E, Zeng L, Salvo N, et al. Update on the systematic review of palliative radiotherapy trials for bone metastases. Clin Oncol ( $R$ Coll Radiol) 2012; 24:112-24.

75. Ahmad SS, Duke S, Jena R, et al. Advances in radiotherapy. BMJ2012; 345:e7765.

76. Hall EJ, Wuu CS. Radiation-induced second cancers: the impact of 3D-CRT and IMRT. Int J Radiat Oncol Biol Phys 2003; 56:83-8.

77. Verellen D, De Ridder M, Linthout N, et al. Innovations in image-guided radiotherapy. Nat ReV Cancer 2007; 7: 949-60.

78. Shang CY, Kasper ME, Kathriarachchi V, et al. Can an alternative backround-corrected [18F] fluorodeoxyglucose (FDG) standard uptake value (SUV) be used for monitoring tumor local control following lung cancer stereotactic body radiosurgery? Int J Cancer Ther Oncol 2014; 2:020317.

79. Martin A, Gaya A. Stereotactic body radiotherapy: a review. Clin Oncol ( $R$ Coll Radiol) 2010; 22:157-72.

80. Rana S, Singh H. Impact of heterogeneities on lateral penumbra in uniform scanning proton therapy. Int J Cancer Ther Oncol 2013; 1:01026.

81. DeLaney TF. Proton therapy in the clinic. Front Radiat Ther Oncol 2011; 43:465-85.

82. Chow MT, Möller A, Smyth MJ. Inflammation and immune surveillance in cancer. Seminars in Cancer Biology 2012; 22: 23-32.

83. Buonaguro L, Petrizzo A, Tornesello ML, Buonaguro F. Translating tumor antigens into cancer vaccines. Clin Vaccine Immunol 2011; 18: 23-34.

84. Melenhorst JJ, Barrett AJ. Tumor vaccines and beyond. Cytotherapy 2011; 13:8-18.

85. Lutz E, Yeo CJ, Lillemoe KD, et al. A lethally irradiated irradiated allogeneic granulocytemacrophage colony stimulating factorsecreting tumor vaccine for pancreatic adenocarcinoma. A Phase II trial of safety, efficacy, and immune activation. Annals of Surgery 2011; 253:328-335.

86. Schlom J. Therapeutic cancer vaccines: Current status and moving forward. J Nat Cancer Inst 2012; 104:599-613.

87. Schwartzentruber DJ, Lawson DH, Richards JM, et al. Gp100 peptide vaccine and interleukin-2 in patients with advanced melanoma. $N$ Engl $J$ Med 2011; 364: 2119-27.

88. Inogés $\mathrm{S}$, de Cerio $\mathrm{AL}$, Villanueva $\mathrm{H}$, et al. Idiotype vaccines for lymphoma therapy. Expert Rev Vaccines 2011; 10:801-9. 
89. Silva J, Garcia V, Lopez-Gonzalez A, Provencio M. MicroRNAs as molecular markers in lung cancer. Int J Cancer Ther Oncol 2013; 1:010111.

90. Bommer GT, Gerin I, Feng Y, et al. p53- mediated activation of miRNA34 candidate tumor-suppressor genes. Curr Bio 2007; 17:1298-307.

91. Shegokar R, Al Shaal L, Mishra PR. SiRNA delivery: challenges and role of carrier systems. Pharmazie 2011; 66:313-8.

92. Lu J, Getz G, Miska EA, et al. MicroRNA expression profiles classify human cancers. Nature 2005; 435:834-8.

93. Ruf P, Lindhofer H. Induction of a long-lasting antitumor immunity by a trifunctional bispecific antibody. Blood 2001; 98:2526-34.

94. Yang W, Soares J, Greninger P, et al. Genomics of Drug Sensitivity in Cancer (GDSC): a resource for therapeutic biomarker discovery in cancer cells. Nucleic Acids Res 2013; 41: D955-61.

95. Parker KA, Glaysher S, Polak M, et al. The molecular basis of the chemosensitivity of metastatic cutaneous melanoma to chemotherapy. J Clin Pathol 2010; 63:1012-20.

96. Glaysher S, Gabriel FG, Cree IA. Measuring gene expression from cell cultures by quantitative reverse-transcriptase polymerase chain reaction. Methods Mol Biol 2011; 731:381-93. 